\title{
REAL TIME CONTROL OF TWIN ROTOR MIMO SYSTEM WITH PID AND FRACTIONAL ORDER PID CONTROLLER
}

\author{
*Tufan DOĞRUER, Department of Electronics and Automation, Tokat Gaziosmanpasa University, Turkey, tufan.dogruer@gop.edu.tr \\ (iD) https://orcid.org/0000-0002-0415-3042) \\ Nusret TAN, Department of Electrical and Electronics Engineering, Inonu University, Turkey, nusret.tan@inonu.edu.tr \\ (iD) https://orcid.org/0000-0002-1285-1991) \\ Received: 03.01.2020, Accepted: 29.04.2020 \\ *Corresponding author \\ Research Article \\ DOI: $10.22531 /$ muglajsci.669738
}

\begin{abstract}
This paper presents real-time control applications for the TRMS system. The twin rotor helicopter model has some complex features which make it difficult to control and therefore it can be used an ideal test setup for control applications. In this study, firstly, twin rotor helicopter model is run in real time and mathematical models are determined. According to the mathematical models, fractional order PID controller designs are realized by using Genetic Algorithm and real time pitch and yaw position control of the twin rotor helicopter model is provided. In the optimization algorithm, fractional order PID controller parameters were determined according to four different integral performance criteria. In real-time control of TRMS, integral performance criteria are compared with each other and the results are presented in figures. The results show that the real-time control of the system has been successfully performed using fractional order PID controller.
\end{abstract}

Keywords: TRMS, PID, Fractional Order PID, Optimization

\section{ÇIFT MOTORLU İKI GİRIS İKI ÇIKIŞLI SISTEMIN PID VE KESİR DERECELİ PID KONTROLÖR İLE GERÇEK ZAMANLI KONTROLÜ}

\section{Özet}

Bu makalede, TRMS sistemi için gerçek zamanlı kontrol uygulamaları sunulmaktadır. Çift motorlu helikopter modeli bazı karmaşı özelliklere sahip olduğu için kontrolü zordur ve kontrol uygulamaları için ideal bir deney düzeneğidir. Bu çalışmada, ilk olarak çift motorlu helikopter modeli gerçek zamanlı çalıştırılarak, matematiksel modelleri belirlenmiştir. Belirlenen matematiksel modellere göre kesir dereceli PID kontrolör tasarımları Genetik algoritma kullanılarak gerçekleştirilmiş ve çift motorlu helikopter modelinin gerçek zamanlı dikey ve yatay eksen kontrolü sağlanmıştır. Optimizasyon algoritmasında, dört farklı integral performans kriterlerine göre kesir dereceli PID kontrolör parametreleri belirlenmiştir. TRMS'nin gerçek zamanlı kontrolünde, integral performans kriterleri birbirleriyle karşılaştırılarak, elde edilen sonuçlar şekiller ile sunulmuştur. Sonuçlar, doğrusal olmayan iki girişi ve iki çıkışı olan bir sistemin gerçek zamanlı kontrolünün kesir dereceli PID kontrolör kullanılarak başarıyla gerçekleștirildiğini göstermektedir.

Anahtar Kelimeler: TRMS, PID, Kesir Dereceli PID, Optimizasyon

Cite

Doğruer, T., Tan, N., (2020). "Real time control of twin rotor MIMO system with PID and fractional order PID controller", Mugla Journal of Science and Technology, 6(0), 1-9.

\section{Introduction}

The control problem of the helicopter that has complex structure is one of the important research topics in control theory. The twin-rotor multi-input multi-output system (TRMS) is a helicopter-like aerodynamic vehicle with propellers operating at both ends driven by direct current motors [1]. TRMS has been designed by Feedback Instruments Corp. to perform control applications in the laboratory environment. The main rotor, one of the two rotors in the structure of TRMS, provides movement on the vertical axis. The tail rotor allows the movement of the TRMS in the horizontal axis. The movement of the TRMS on the vertical and horizontal axis is controlled by the pitch angle and the yaw angle, respectively [2]. The electromechanical model of TRMS is shown in Fig. 1.

TRMS is considered an important engineering problem as it allows some complex, nonlinear situations and outputs to be taken into account. The purpose of the controller design for TRMS is to ensure that the TRMS is placed in the desired pitch and yaw position, despite parameter uncertainties in the system. Studies on the TRMS model have focused on determining the mathematical model of the system and developing various methods for controlling the system. Juang et al. [3] proposed a method for controlling the nonlinear 
MIMO system using Genetic Algorithm with PID controller. The aim of their work is to move the TRMS to a desired position and to ensure that it follows a specific path efficiently. They have used the ITSE performance criterion as a fitness function in the optimization algorithm. They emphasized that the proposed method performed a successful control in the TRMS system. Rotondo et al. [4] presented a study on semi-linear modeling of TRMS, determining and controlling the mathematical model of the system. Chalupa et al. [5] carried out experimental studies on modeling of TRMS. In another study, Juang et al. [6] presented several classical control methods and intelligent control methods for TRMS. For similar studies [7-12] can be examined. The optimization algorithm used in determining the control parameters reflects the original aspect of this study. In the optimization algorithm, using four different integral performance criteria as the objective function and determining the controller parameters according to these objective functions adds depth to the study. The fact that the controller structure used is fractional order controller seems to be one of the most important differences of the study.

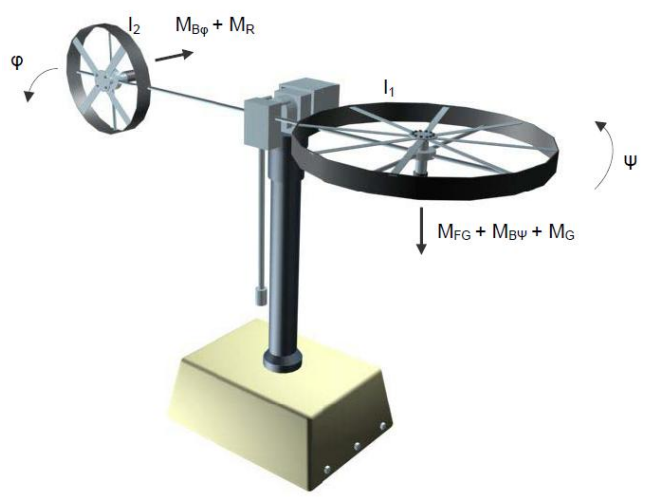

Figure 1. Electromechanical model of TRMS.

The optimization process can be defined as determining the best of the alternative solutions available and is one of the effective methods used to determine the controller parameters in the control theory. The objective of optimization problems is to find variable values that optimize the solution. In literature, classical methods and artificial methods for optimization problems many optimization techniques have been proposed, including intelligent methods. Research shows that designs using heuristic algorithms give more successful results than classical design methods [13]. Genetic Algorithm is an evolutionary algorithm introduced by Holland and is widely used in optimization processes. In this paper, Genetic Algorithm is preferred because it provides more successful results than many optimization methods. The objective (fitness) function, decision variables and constraints are the components of an optimization problem. In this study, integral performance criteria are used as fitness function. Integral performance criteria are used to minimize the error of the control system in assessing the performance of a control system.
In this study, the real-time mathematical model of TRMS is determined and the experimental study which performs pitch and yaw position control using fractional order PID controller is included. Fractional order PID controller parameters were determined by an optimization method using Genetic Algorithm. In the optimization method, controller parameters were determined according to four different integral performance criteria.

The rest of this paper is organized as follows. In the second section, a brief overview of the PID and fractional order PID controller structures and optimization method used in the paper is discussed. The third section discusses the determination of the realtime mathematical model of the TRMS system. In addition, the pitch and yaw position control of the TRMS was performed in real-time, and the results were presented. Finally, the results are discussed in the last section.

\section{Controller Design}

In this section, brief information about the structure of the conventional PID and fractional order PID controller is given and the optimization method used in the study is presented.

\subsection{PID and Fractional Order PID Controllers}

PID controllers are often preferred due to many advantages in control cycles [14]. The widespread use of PID controllers in the industry has increased the interest in determining their parameters. There are three parameters in the PID controller structure that must be calculated as $K_{p}, K_{i}$ and $K_{d}$. The transfer function of the conventional PID controller is given in Equation (1) [14].

$$
C(s)=K_{p}+\frac{K_{i}}{s}+K_{d} s
$$

Where, $K_{p}, K_{i}$ and $K_{d}$ show the coefficient of the proportional term, the coefficient of the integral term and the coefficient of the derivative term, respectively.

In recent years, interest in fractional order PID controllers has increased significantly. The fractional order PID controller introduced by Podlubny is the generalization of the PID controller. It has also been shown by Podlubny that the fractional order PID controller provides a better response compared to the conventional PID controller for fractional order systems. The fractional order PID has two extra parameters, $\lambda$ and $\mu$, compared to the conventional PID controller where, $\lambda$ is the degree of the integral term, and $\mu$ is the degree of the derivative term. The equation of the fractional order PID controller is given in Equation (2) [15].

$$
C(s)=K_{p}+\frac{K_{i}}{s^{\lambda}}+K_{d} s^{\mu}
$$


If the $\lambda$ and $\mu$ parameters are 1 , the fractional order PID controller becomes the PID controller. The block diagram showing the fractional order PID controller structure is given in Fig. 2.

In high-order systems, systems with long time delays, and nonlinear systems, the fractional order PID controller performs superior to the conventional PID controller. Also, stability and robustness are low in PID controlled systems, while more stable and robust control is achieved with fractional order PID controllers [16].

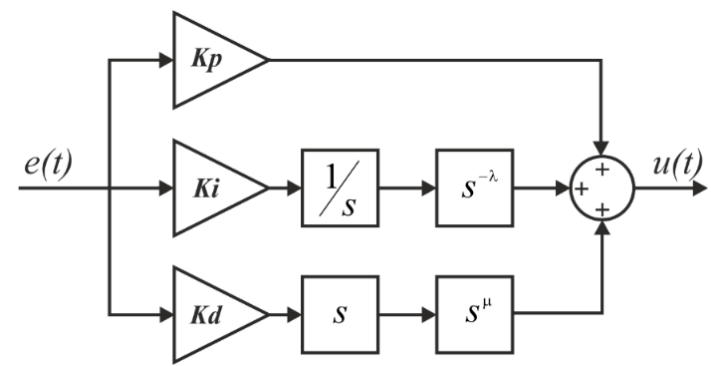

Figure 2. Structure of fractional order PID controller.

\subsection{Optimization Method}

The block diagram of the model used for determining the controller parameters is shown in Fig. 3.

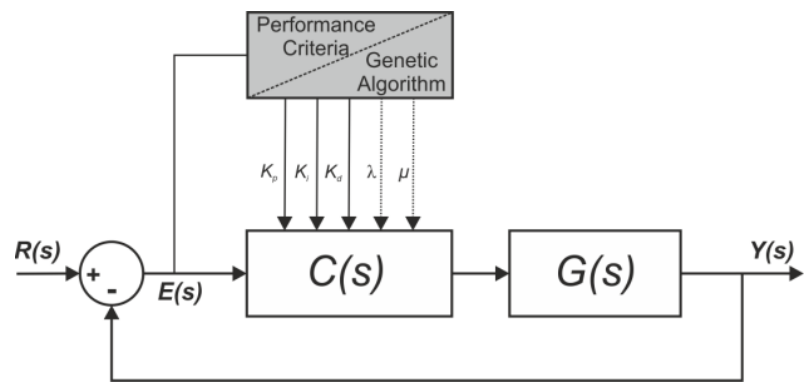

Figure 3. Block diagram of the feedback control system used in the optimization process.

In an ideal control system, the output signal tries to follow the reference input with zero error, but this is practically impossible. Often, when evaluating the performance of a control system, the transient and steady-state behavior of the system against the unit step response is examined. In particular, the time response performance characteristics of the system such as the maximum percentage overshoot, rise, settling and peak time of the transient response are considered. It is desirable that these parameters be of small value, but it is difficult to design according to these parameters. Therefore, integral performance criteria have been developed to calculate optimal control parameters based on error in closed loop control system. In controller design, optimal controller parameters can be found by minimizing the error occurring in the controlled system using integral performance criteria. Integral performance criteria are defined as the objective function in optimization algorithms and enable minimization.

First, in 1953, Graham and Lathrop [17] used the performance criteria of the integral of the square of the error (ISE) and the integral of the absolute of the error (IAE). ISE and IAE are given by Equation (3) and Equation (4), respectively [18].

$$
\begin{aligned}
& J=\int_{0}^{\infty} e^{2}(t) d t \\
& J=\int_{0}^{\infty}|e(t)| d t
\end{aligned}
$$

Then the integral performance criteria were developed by integral of the square of the time-weighted error (ITSE) and the integral of the absolute of the timeweighted error (ITAE). The ITSE criterion is calculated by Equation (5). The ITAE criterion is calculated by Equation (6) [18].

$$
\begin{aligned}
& J=\int_{0}^{\infty} t \cdot e^{2}(t) d t \\
& J=\int_{0}^{\infty}|t \cdot e(t)| d t
\end{aligned}
$$

Here, $e(t)$ is the error and $t$ is time.

The idea of Genetic Algorithms proposed by John Holland is an optimization method that takes its principle from the theory of evolution and has a wide range of applications. Charles Darwin's principle of the survival of the best was a start for John Holland, and he began his studies on Genetic Algorithms in the early 1970s [19]. The first general form of Genetic Algorithms which yields more successful results than conventional optimization methods is stated by Goldberg [20]. Genetic algorithm, by scanning a specific location of the solution space, reaches the solution in a short time.

The flowchart of the Genetic Algorithm is as follows [21]: 


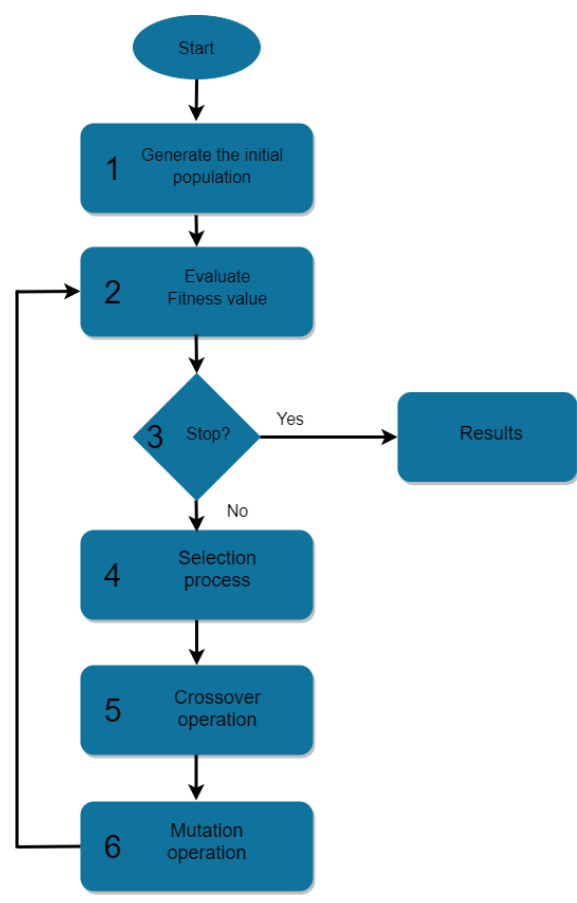

Figure 4. Genetic Algorithm flowchart.

The first step of Genetic Algorithm is to determine the initial population. Here, different population sizes can be determined. If the specified population is too small, a detailed search may not be possible. But the convergence and the achievement of the result is fast. If the population is too large, it may take a long time to reach the conclusion. Often, Genetic Algorithms start with a random population. The approach of the individuals in the population to the solution is evaluated by "fitness or objective function". First, the fitness values of the genes are calculated. In each iteration, the selection process is made considering the fitness value. The best chromosome determined according to the fitness values is the chromosome that gives the optimum solution of the problem. Are the criteria sought? If yes, the algorithm stops. If no, proceed to Step 4. The selection process is carried out so that better individuals can be transferred to subsequent generations. In the fifth step, crossover operation is performed. Crossover is performed to combine the characteristics of existing good chromosomes to obtain more suitable chromosomes. In the sixth step, mutation is performed to preserve genetic diversity in the population. The algorithm continues until the best solution is found.

In reproduction, each repetition is called an iteration. Increasing the number of iterations in optimization improves the quality of the solution, but there is no general rule on how many iterations are required to reach the most appropriate solution. Here, the user determines the number of iterations according to the type of problem. In this paper, the population size and the number of iterations were set to 30 and 50, respectively.

Studies to date have shown that Genetic Algorithms are quite successful in finding the most appropriate solutions. Problems that cannot be solved by analytical methods are solved with Genetic Algorithms in a short time.

\section{Experimental Study}

In this section, the mathematical models of TRMS are determined and the pitch and yaw position controls of TRMS are performed in real time. The experimental set of TRMS is shown in Fig. 5. In this study, Oustaloup's 5th order integer order approximation method was used to model the fractional order PID controller [22].

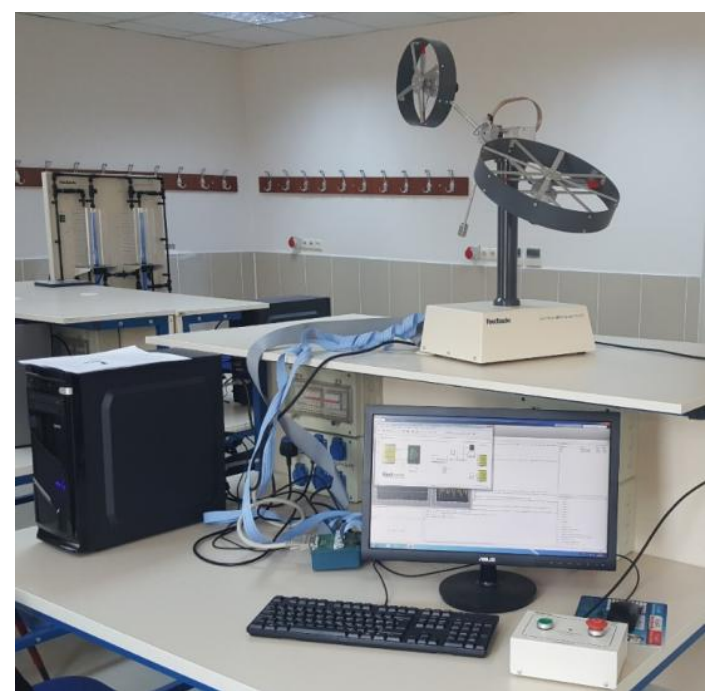

Figure 5. TRMS experimental set.

\subsection{Determination of the Mathematical Model of TRMS}

As shown in Fig. 6, the TRMS has a two-input, $u_{1}$ and $u_{2}$ and two-output, $\psi$ and $\varphi$, structure. Dynamic crosscoupling is one of the main features of TRMS. As shown in the block diagram of the TRMS, two models are determined for pitch and yaw motion path. Due to the nonlinear effects of pitch motion, the main rotor has an effect on the yaw motion. This effect is shown by the cross-path model from pitch motion. Similarly, the torque of the yaw equilibrium motor affects the free movement at the pitch position. This effect can also be demonstrated from the yaw equilibrium motion with the cross path model.

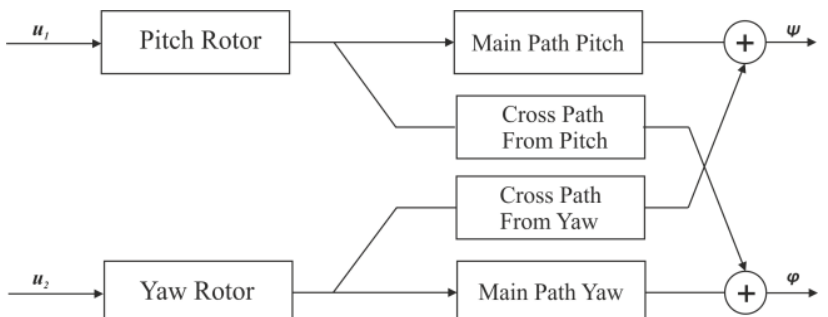

Figure 6. TRMS simplified system schematic [23].

By operating TRMS in real time, mathematical models can be determined with 'System Identification Toolbox' tool of the Matlab program.

Using the real-time Simulink model shown in Fig. 7, the TRMS is given a multi-sinusoidal signal obtained by summing sinusoidal signals at different frequencies. 
TRMS was operated for a sufficient period of time (100 $\mathrm{sec}$ ) to receive data from the system. The data on output signals of TRMS as a response to the input signals were obtained. By entering the input and output data in Matlab, the model for the pitch motion path of the TRMS was obtained.
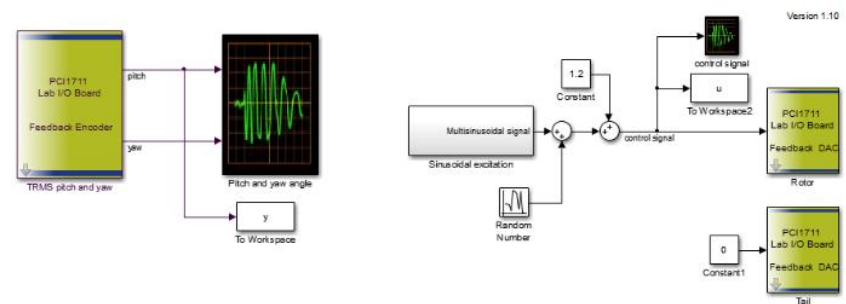

Figure 7. Simulink model of the real time TRMS pitch position identification.

Equation (7) represents the mathematical model of pitch motion path.

$$
G_{11}(s)=\frac{2.57}{s^{3}+1.869 s^{2}+4.916 s+7.515}
$$

Similarly, the mathematical model of the yaw motion path is determined as in Equation (8).

$$
G_{22}(s)=\frac{0.1511}{s^{2}+0.7281 s+0.3111}
$$

Equation (9) and Equation (10) show the mathematical models of pitch cross path and yaw cross path, respectively.

$$
\begin{gathered}
G_{12}(s)=\frac{0.008407}{s^{2}+0.7783 s+0.02515} \\
G_{21}(s)=\frac{0.055045 s+0.08529}{s^{2}+0.2527 s+4.837}
\end{gathered}
$$

The fractional order PID controllers can be designed using the mathematical models.

Furthermore, Fig. 8 shows the similarity of the actual system and model output for pitch position. From the figure, it is seen that the linear model defined by Equation 7 follows the actual system very closely.

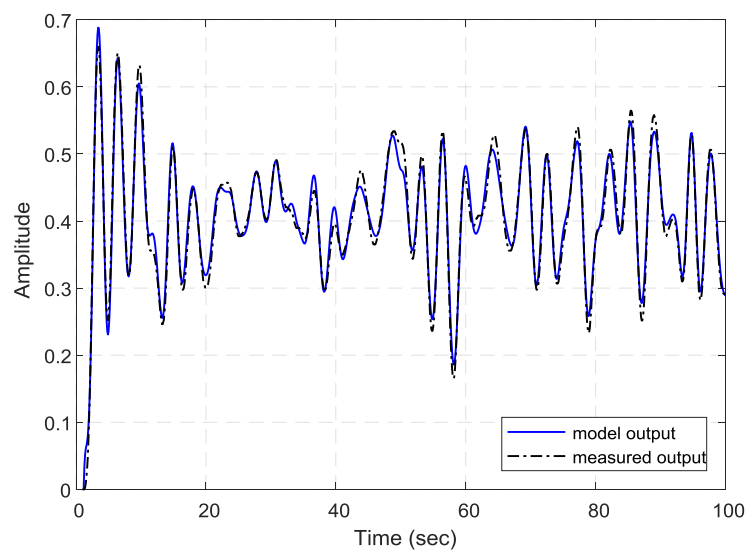

Figure 8. Measured (actual) and simulated model output for pitch position

\subsection{Pitch Position control of TRMS}

Fig. 9 shows a real-time Simulink model of pitch position control for TRMS. This model is supplied by Feedback Instruments with the prototype TRMS. In the model, the pitch position control of TRMS is controlled by PID controller. Here, the PID controller is given by Equation (11) [23].

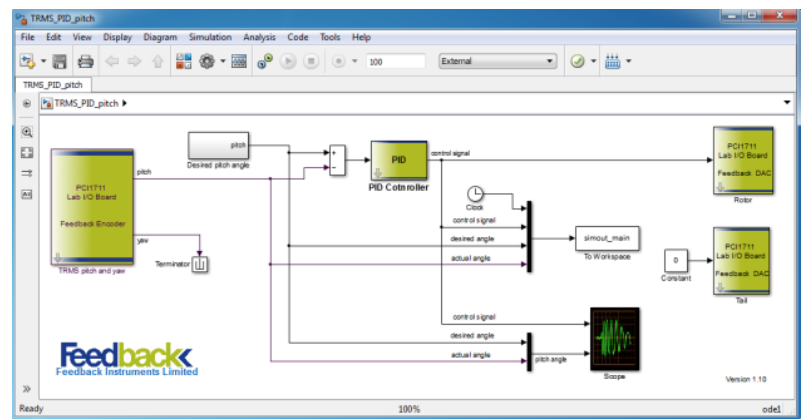

Figure 9. Pitch position path Simulink model.

$$
C_{p i d}(s)=5+\frac{8}{s}+10 s
$$

In this section, fractional order PID controller is designed for pitch position control of the TRMS. In order to determine the controller parameters, the optimization algorithms were formed according to each integral performance criterion by taking the mathematical model in Equation (7). Genetic Algorithm based optimization algorithms were used to obtain controller parameters. The obtained fractional order PID controller parameters and fitness function values are given in Table 1.

Table 1. FOPID controller parameters and fitness function values for pitch position.

\begin{tabular}{ccccc}
\hline & IAE & ISE & ITAE & ITSE \\
\hline$K_{p}$ & 7.804 & 4.285 & 9.996 & 4.971 \\
$K_{i}$ & 9.961 & 9.997 & 9.992 & 7.917 \\
$K_{d}$ & 6.538 & 9.982 & 7.454 & 9.117 \\
$\lambda$ & 0.975 & 0.878 & 0.988 & 0.838 \\
$\mu$ & 1.199 & 1.099 & 1.195 & 1.094 \\
$J$ & 0.6210 & 0.2714 & 0.8338 & 0.213 \\
\hline
\end{tabular}




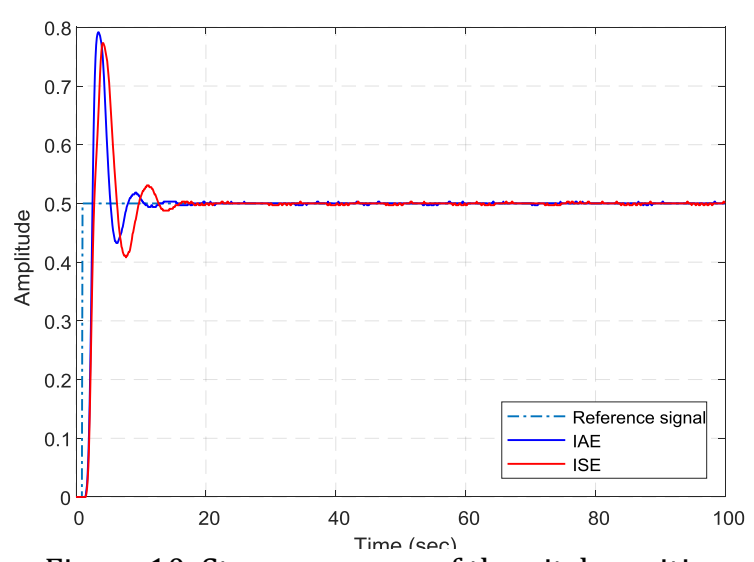

Figure 10. Step responses of the pitch position controlled by FOPID based IAE and ISE.

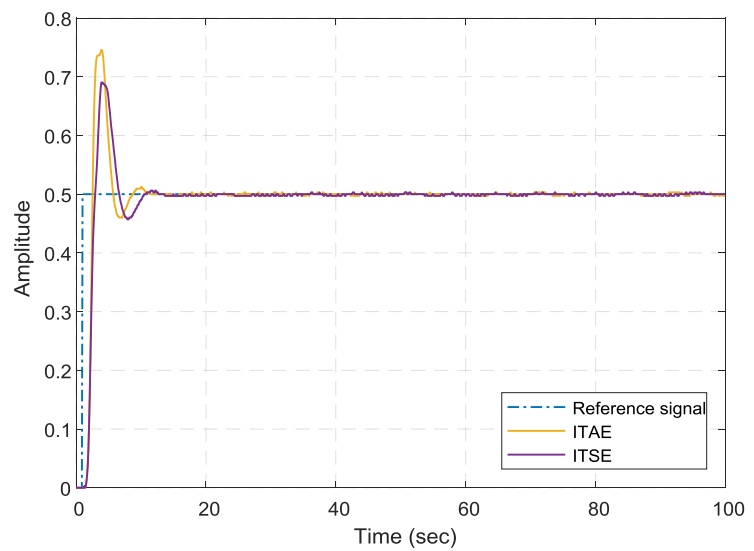

Figure 11. Step responses of the pitch position controlled by FOPID based ITAE and ITSE.

In the model given in Fig. 9, the PID controller block is removed and a fractional order PID controller block is added instead. The closed loop step responses of the systems obtained by overwriting the controller parameters in Table 1 in the Simulink model and running TRMS in real time are given in Fig. 10 and Fig. 11. Fig. 10 shows the step responses obtained by applying the controllers determined according to IAE and ISE performance criteria to the TRMS system. In Fig. 11 , the step responses obtained by applying the controllers determined according to ITAE and ITSE performance criteria to the TRMS system are given. In Fig. 10 and Fig. 11, it is seen that the best performance is provided by ITSE based controller design.

The PID controller given by Equation (11) and the fractional order PID controller designed based on ITSE are compared in Fig. 12. It is evident that the fractional order PID controller performs better than the PID controller. The maximum overshoot value of the system is $42.94 \%$ when controlled by conventional PID, but decreases to $38.03 \%$ when controlled by fractional order PID. Settling time is $14.27 \mathrm{~s}$ in the PID controlled system, while it decreases to $9.97 \mathrm{~s}$ when controlled by fractional order PID. Further, the control signals of the systems controlled by fractional order PID and PID controllers are given in Fig. 13.

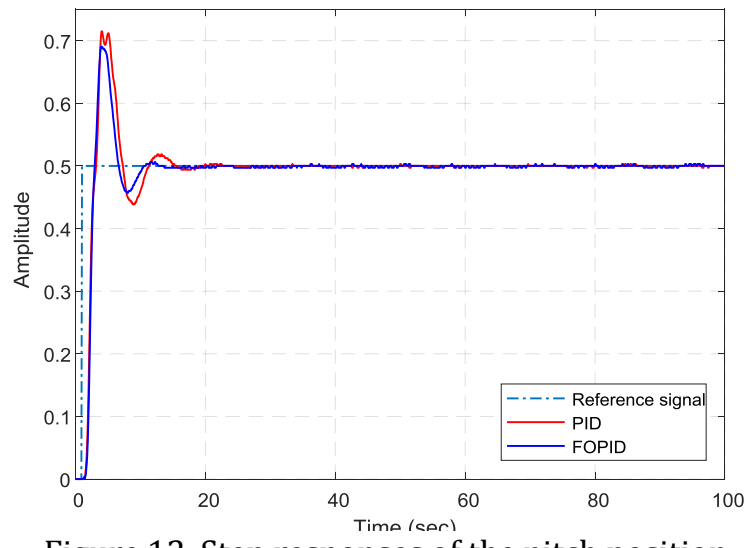

Figure 12. Step responses of the pitch position controlled by PID and FOPID.

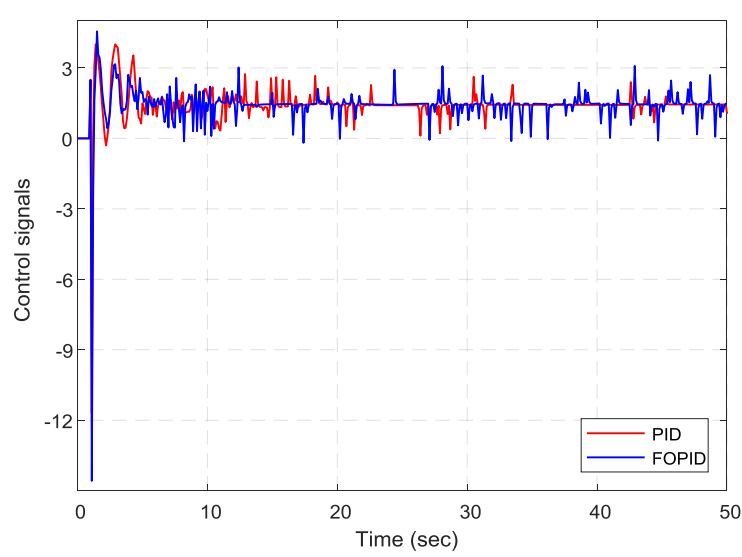

Figure 13. Control signals of the pitch position controlled by PID and FOPID.

Furthermore, the time response characteristics of the systems are given in Table 2 .

Table 2. The time response specifications

\begin{tabular}{ccccc}
\hline & IAE & ISE & ITAE & ITSE \\
\hline$t_{r}(s)$ & 0.6511 & 0.7747 & 0.6489 & 0.8735 \\
$t_{s}(s)$ & 9.8740 & 14.3740 & 10.4760 & 9.9740 \\
$t_{p}(s)$ & 3.40 & 4.10 & 3.90 & 3.90 \\
$M_{p}(\%)$ & 58.28 & 54.6012 & 50.00 & 38.0368 \\
\hline
\end{tabular}

\subsection{Yaw Position Control of TRMS}

The real-time Simulink model of the yaw position control of TRMS is as shown in Fig. 14. In the model, the yaw position control of TRMS is controlled by PID controller. Here, the PID controller is as given in Equation (12) [23].

$$
C_{p i d}(s)=2+\frac{0.5}{s}+5 s
$$




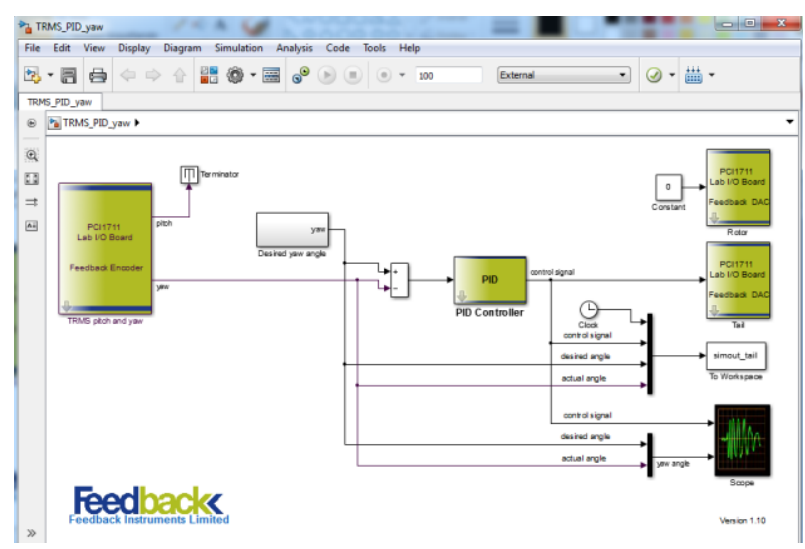

Figure 14. Yaw position path Simulink model.

Here, the fractional order PID controller is designed for yaw position control of TRMS. In order to design the fractional order PID controller according to the mathematical model in Equation (8), optimization models have been created. Optimization is started by entering the lower and upper bound limit values of the controller parameters in the optimization. When fitness values are achieved, optimization stops and controller parameters are determined. Fractional order PID controller parameters obtained using Genetic Algorithm are given in Table 3.

Table 3. FOPID controller parameters for yaw position control.

\begin{tabular}{ccccc}
\hline & IAE & ISE & ITAE & ITSE \\
\hline$K_{p}$ & 4.99 & 4.998 & 3.961 & 4.999 \\
$K_{i}$ & 2.578 & 3.72 & 2.821 & 2.544 \\
$K_{d}$ & 4.995 & 4.991 & 4.976 & 4.999 \\
$\lambda$ & 0.95 & 0.793 & 0.949 & 0.948 \\
$\mu$ & 0.854 & 0.95 & 0.681 & 0.86 \\
$J$ & 1.1646 & 0.5600 & 2.9076 & 0.2797 \\
\hline
\end{tabular}

Fig. 15 and Fig. 16 show closed loop step responses of systems controlled by the fractional order PID controller. Fig. 15 shows the step responses obtained by applying the controllers determined according to IAE and ISE performance criteria to the TRMS system. In Fig. 16, the step responses obtained by applying the controllers determined according to ITAE and ITSE performance criteria to the TRMS system are given. In Fig. 15 and Fig. 16, it is seen that the best performance is provided by ITSE based controller design. Also, the PID controller given by Equation (12) and the fractional order PID controller designed based on ITSE are compared in Fig. 17. It is clear that the fractional order PID controller performs better. Also, the time response characteristics of the systems are presented in Table 4. Moreover, the control signals of the systems controlled by fractional order PID and conventional PID controllers are given in Fig. 18. The results show that a real-time system with nonlinear two inputs and two outputs is successfully controlled using the fractional order PID controller.

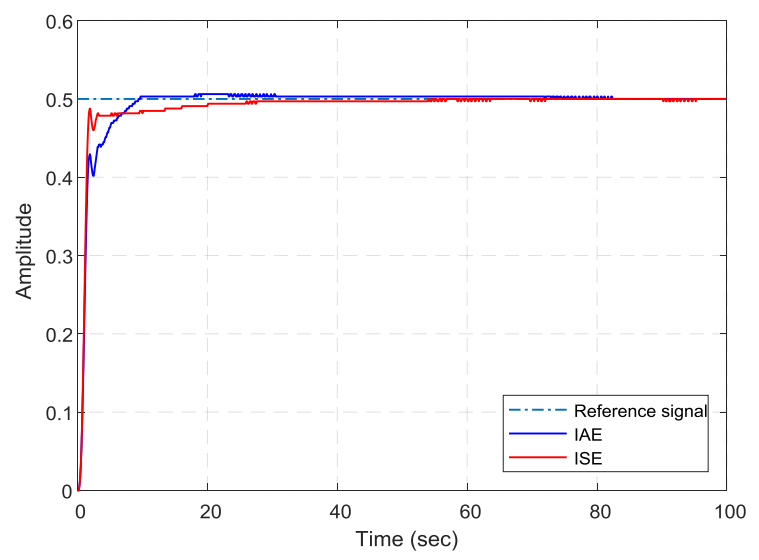

Figure 15. Step responses of the yaw position controlled by FOPID based IAE and ISE.

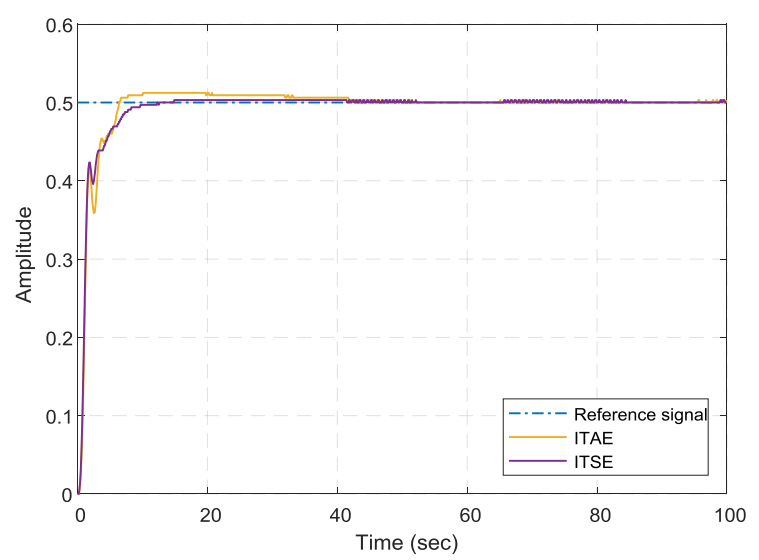

Figure 16. Step responses of the yaw position controlled by FOPID based ITAE and ITSE.

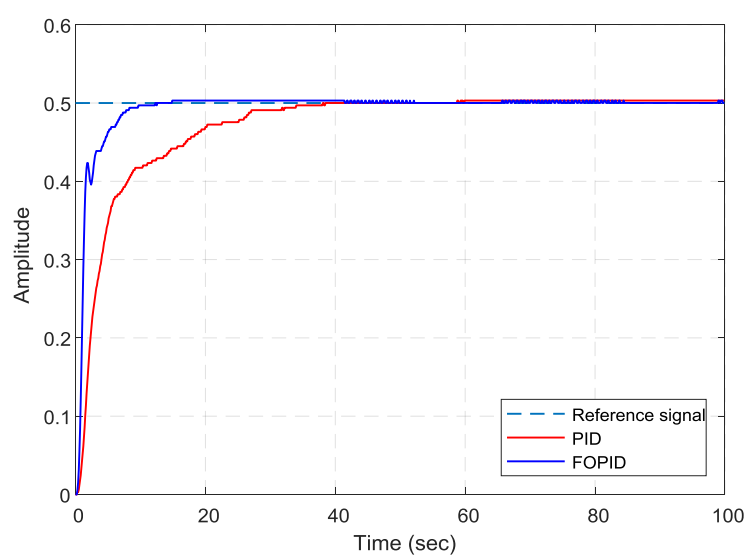

Figure 17. Step responses of the yaw position controlled by PID and FOPID.

Table 4. The time response specifications

\begin{tabular}{ccccc}
\hline & IAE & ISE & ITAE & ITSE \\
\hline$t_{r}(s)$ & 3.68 & 0.9925 & 3.0300 & 3.7913 \\
$t_{s}(s)$ & 7.9740 & 16.0740 & 6.2720 & 7.7740
\end{tabular}




\begin{tabular}{ccccc}
\hline$t_{p}(s)$ & 18.10 & 54.10 & 10.10 & 14.90 \\
$M_{p}(\%)$ & 1.2270 & 0 & 1.8293 & 0.6135 \\
\hline
\end{tabular}

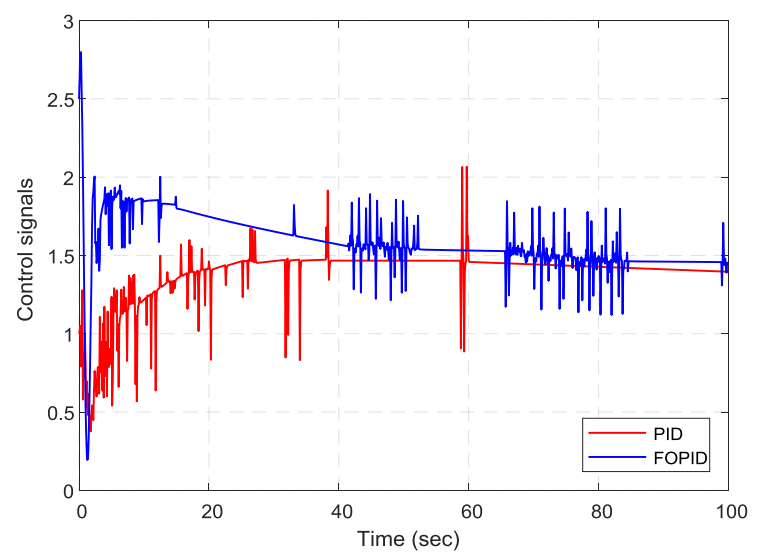

Figure 18. Control signals of the yaw position controlled by PID and FOPID.

The first version of this paper was presented in the symposium TOK2019.

\section{Conclusion}

In this paper, the pitch and yaw position control of TRMS has been realized in real time by optimization method. Fractional order PID controller parameters were determined according to different integral performance criteria using Genetic Algorithm in optimization algorithm. The performance comparisons of the controllers were made by real-time control of both pitch and yaw position of the TRMS controlled by PID controller and fractional order PID controller. In addition, the responses obtained according to four different integral performance criteria were compared.

According to the results, ITSE-based controller design is more successful than the others. When ITSE-based fractional order PID controller is used to control the system, the settling time of the system for pitch position control decreases by approximately 4 seconds, while the yaw position control decreases by 24 seconds. Besides, it has been observed that the maximum overshoot value is reduced by approximately $5 \%$ by using the ITSEbased fractional order PID controller for pitch position control.

The results show that the real-time control of a nonlinear system with two inputs and two outputs has been successfully performed using fractional order PID controller.

\section{References}

[1] Bayrak, A., Dogan, F., Tatlicioglu, E., and Ozdemirel, B., "Design of an experimental twin - rotor multi - input multi-output system," Computer Applications in Engineering Education, vol. 23, no. 4, pp. 578-586, 2015.

[2] Kavuran, G., Ates, A., Alagoz, B. B., and Yeroglu, C., "An Experimental Study on Model Reference Adaptive Control of TRMS by Error-Modified
Fractional Order MIT Rule," Control Enginnering and Applied Informatics, vol. 19, no. 4, pp. 101-111, 2017.

[3] Juang, J.-G., Huang, M.-T., and Liu, W.-K., "PID control using presearched genetic algorithms for a MIMO system," IEEE Transactions on Systems, Man, and Cybernetics, Part C (Applications and Reviews), vol. 38, no. 5, pp. 716-727, 2008.

[4] Rotondo, D., Nejjari, F., and Puig, V., "Quasi-LPV modeling, identification and control of a twin rotor MIMO system," Control Engineering Practice, vol. 21, no. 6, pp. 829-846, 2013.

[5] Chalupa, P., Přikryl, J., and Novák, J., "Modelling of twin rotor MIMO system," Procedia Engineering, vol. 100, pp. 249-258, 2015.

[6] Juang, J.-G., Lin, R.-W., and Liu, W.-K., "Comparison of classical control and intelligent control for a MIMO system," Applied Mathematics and Computation, vol. 205, no. 2, pp. 778-791, 2008.

[7] Ahmad, S., Chipperfield, A., and Tokhi, M., "Dynamic modelling and open-loop control of a twin rotor multi-input multi-output system," Proceedings of the Institution of Mechanical Engineers, Part I: Journal of Systems and Control Engineering, vol. 216, no. 6, pp. 477-496, 2002.

[8] Ahmad, S., Chipperfield, A., and Tokhi, O., "Dynamic modeling and optimal control of a twin rotor MIMO system," presented at the Proceedings of the IEEE 2000 National Aerospace and Electronics Conference, 2000.

[9] Ahmad, S., Shaheed, M., Chipperfield, A., and Tokhi, M., "Nonlinear modelling of a twin rotor MIMO system using radial basis function networks," presented at the Proceedings of the IEEE 2000 National Aerospace and Electronics Conference, 2000.

[10] Juang, J.-G., Liu, W.-K., and Lin, R.-W., "A hybrid intelligent controller for a twin rotor MIMO system and its hardware implementation," ISA transactions, vol. 50, no. 4, pp. 609-619, 2011.

[11] Rahideh, A., Bajodah, A. H., and Shaheed, M. H., "Real time adaptive nonlinear model inversion control of a twin rotor MIMO system using neural networks," Engineering Applications of Artificial Intelligence, vol. 25, no. 6, pp. 1289-1297, 2012.

[12] Shih, C. L., Chen, M. L., and Wang, J. Y., "Mathematical model set-point stabilizing controller design of a twin rotor MIMO system," Asian journal of control, vol. 10, no. 1, pp. 107-114, 2008.

[13] Mirjalili, S. and Lewis, A., "The whale optimization algorithm," Advances in engineering software, vol. 95, pp. 51-67, 2016.

[14] Åström, K. J. and Hägglund, T., PID controllers: theory, design, and tuning. Instrument society of America Research Triangle Park, NC, 1995.

[15] Podlubny, I., "Fractional-order systems and $P^{\lambda} D^{\mu_{-}}$ controllers," IEEE Transactions on automatic control, vol. 44, no. 1, pp. 208-214, 1999. 
[16] Shah, P. and Agashe, S., "Review of fractional PID controller," Mechatronics, vol. 38, pp. 29-41, 2016.

[17] Graham, D. and Lathrop, R. C., "The synthesis of optimum transient response: criteria and standard forms," Transactions of the American Institute of Electrical Engineers, Part II: Applications and Industry, vol. 72, no. 5, pp. 273-288, 1953.

[18] Atherton, D., Control engineering. Bookboon, 2009.

[19] Holland, J. H., Adaptation in natural and artificial systems: an introductory analysis with applications to biology, control, and artificial intelligence. MIT press, 1992.

[20] Goldberg, D. E. and Deb, K., "A comparative analysis of selection schemes used in genetic algorithms," in Foundations of genetic algorithms, vol. 1: Elsevier, 1991, pp. 69-93.
[21] Jayachitra, A. and Vinodha, R., "Genetic algorithm based PID controller tuning approach for continuous stirred tank reactor," Advances in Artificial Intelligence, vol. 2014, p. 9, 2014.

[22] Oustaloup, A., Levron, F., Mathieu, B., and Nanot, F. M., "Frequency-band complex noninteger differentiator: characterization and synthesis," IEEE Transactions on Circuits and Systems I: Fundamental Theory and Applications, vol. 47, no. 1, pp. 25-39, 2000.

[23] TRMS, Twin Rotor MIMO System Control Experiments Manuel, 33-949S: Feedback Instruments Ltd., Sussex, U.K., 2010. [Online]. Available. 